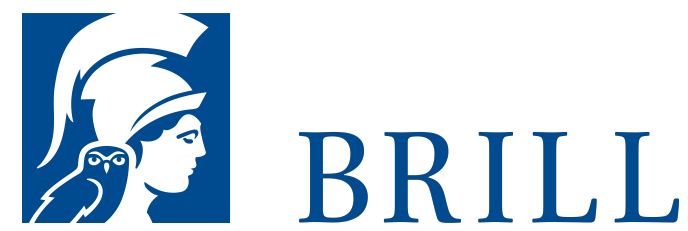

\title{
Benjamins Bilder
}

Grafik, Malerei und Fotografie in der Passagenarbeit

Author: Steffen Haug

Walter Benjamin beschäftigte sich für seine Passagenarbeit (1927-1940) auch ausgiebig mit Druckgrafiken, Gemälden und Fotografien des 19. Jahrhunderts. Diese Bilder werden hier erstmals identifiziert, in einem umfassenden Katalog dokumentiert und in ihrem Stellenwert für sein Werk erläutert. Die Untersuchung widmet sich insbesondere den Recherchen, die Benjamin 1935/36 im Cabinet des Estampes, der Grafiksammlung der Bibliothèque nationale, in Paris durchführte. Seine rund 9o Notizen zu den Bildern wurden zwar im Passagen-Werk (1982) abgedruckt, doch blieben die Werke selbst überwiegend unbekannt. Sie stammen von Künstlern wie Grandville, Meryon oder Daumier, aber auch von anonymen Zeichnern. Die Studie rekonstruiert Benjamins Recherchen und erläutert die Bedeutung der Bilder in den thematischen Zusammenhängen des Passagen-Projekts. Der Vergleich mit der Theorie im Kunstwerk-Aufsatz zeigt, dass Benjamin auch den Medienwandel in der frühen Moderne im Blick hatte. Das Buch macht deutlich, dass Benjamins Überlegungen im PassagenProjekt auf konkrete Bilder bezogen waren.

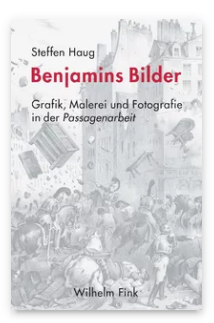

Pages: 592 Seiten, $307 \mathrm{~s} / \mathrm{w}$ und 31 farb. Abb. Language:

German

Subjects: 19 th \& 2oth Century

Philosophy, Philosophy

Publisher: Brill | Fink

E-Book (PDF)

Released online: 17 Nov 2017

ISBN: $978-3^{-}$

8467-5992-9

List price

Paperback

Publication date: 20 Oct 2017

ISBN: 978-3-

7705-5992-3

List price 
Steffen Haug ist Wissenschaftlicher Mitarbeiter am Institut für Kunst- und Bildgeschichte der Humboldt-Universität zu Berlin für die Ausgabe der „Briefe“ Aby Warburgs. Vorher war er an zahlreichen Ausstellungen und Publikationen beteiligt. Er promovierte mit der Arbeit „Anschauliche Dokumentation. Walter Benjamins Bilder-Studien für die Passagenarbeit" in Berlin. Außerdem ist er seit 2007 Redakteur bei der internationalen Fachliste für Kunstgeschichte H-ArtHist.

For more information see brill.com

Order information: Order online at brill.com +44330 3330049 | customerservices@brill.com Submission information: brill.com/authors

Titles published by Brill | Fink, Brill | mentis or Brill | Schöningh: +49(o)71 5413279216 | brill@brocom.de 